\title{
An Assessment of the Level of Occupational Stress among Police Officers in the Sebokeng Cluster
}

\author{
R.K. Mashego \\ Department of Human Resources Management, Vaal University of Technology, \\ Vanderbijpark, Republic of South Africa \\ kmashego@4gmail.com \\ Dr. P.Q. Radebe \\ Department of Human Resources Management, Vaal University of Technology, \\ Vanderbijpark, Republic of South Africa \\ patrick@vut.ac.za
}

\section{Doi:10.5901/mjss.2015.v6n1s1p253}

\section{Abstract}

Occupational stress among police officers is an important area of research because of the realisation that less stressed police officers are more effective and they tend to stay longer with the employing department. The spinoffs of longer stay with the safety and security department are, inter alia, less training costs on replacement staff, utilisation of more experienced staff in critical safety and security areas, and organisational commitment. A self-administered questionnaire was used to collect data from 276 police officers. A stratified random sampling technique was utilised to draw units of analysis for the study. A response rate of $75 \%$ was obtained. Responses were analysed using frequency analysis. The results confirmed that police officers in the Sebokeng Cluster experienced role conflict. The findings from the study were also that police officers did not experience role overload and role ambiguity.

Keywords: occupational stress; role overload; role ambiguity; role conflict.

\section{Introduction}

Policing is among the top four occupations which are reported to be most stressful by both occupational physicians and psychiatrists, something which could be attributed to high rates of crime and violence in the country (Jorgensen \& Rothmann, 2008). Police officers are usually the first at scenes of murder, suicides or accidents and the last to leave such scenes. At such scenes death or injury is a possibility. In general, exposure to danger, violence and having to exercise discretion under critical circumstances by police officers, are factors that could lead to occupational stress (Bucker \& Wiecko, 2007). Previous research among police officers focused on stress in general, and less on stress as it emanates from work-related issues (occupational stress). There is no research on occupational stress among police officers in the Sebokeng Cluster. It is for this reason that the current research aimed to assess the level of occupational stress among police officers in the Sebokeng Cluster. Occupational stress is defined as "a situation wherein work-related factors interact with the worker to change their psychological and/or physiological condition in such a way that an individual is forced to deviate from normal functioning" (Richardson \& Rothstein, 2008). The work-related factors or sources of occupational stress are categorised as role conflict, role overload and role ambiguity (Vecchio, 2000).

\section{Literature Review}

\subsection{Role conflict}

Role conflict occurs when two conflicting demands compete with one another and an employee is unable to fulfill both sets of demands (Aamodt, 2010). Slocum and Hellriegel (2007) add that an employee can experience role conflict when he/she carries out tasks that are not perceived to be part of one's job role. The authors further argue that performing job duties that are in conflict with personal values may lead to role conflict. An example is an employee who is expected to work overtime on Saturday and at the same time be expected to attend a child's event on Saturday at school. Role 
conflict is of four types, namely, intra-sender conflict, inter-sender conflict, inter-role conflict and person-role conflict (Biseul, 2011). Intra-sender conflict refers to a situation where an employee is asked to accomplish two conflicting objectives (Mohr \& Puck, 2003). A request by a manager for a group member to increase speed and decrease errors could result in this type of conflict. Inter-sender conflict occurs when an employee is asked to behave in such a manner that a manager will be pleased with the results whilst another manager will not be satisfied (DuBrin, 2002). Employees experience inter-role conflict when the different role senders' expectations towards the different roles an employee plays are incompatible with one another (Steiber, 2009). Finally, person-role conflict denotes the incompatibility of job roles with an employee's needs, aspirations, and/or values. Role conflict has been found to create and increase occupational stress (De Sousa, 2009). 2.2 Role ambiguity Role ambiguity is defined as "insufficient information, unclear information and uncertainty about employees' expected performance and job behaviours" (Barling, Kelloway \& Frone, 2005). Previous research indicates that role ambiguity may be caused by changes in technology, influence of social structures in an organisation, new personnel entering an organisation, the appointment of a new supervisor, and changes in jobs emanating from new job offers, transfers or promotions (Matthewman, Rose \& Hetherington, 2009). Occupational stress that is caused by changes in technology is known as technostress. Technostress is defined as "a condition resulting from the inability of an individual to adapt to the introduction of and orientation of employees to a new technology" (Yu, Kuo, Chen, Yang, Yang \& Hu, 2009). Role ambiguity may occur as a result of the influence of social structures in a work situation. A social structure is considered as "the steady pattern of social relationships that exist within a particular group or society" (Eighner, 2009). The social structure commonly found in safety and security clusters is Community Police Forum (CPF). CPF is involved in community policing in which case a partnership between the community and the police is formed in order to find creative solutions for contemporary community problems, crime and other related matters. In a scene of crime a police officer may experience role ambiguity when he/she wishes to meet the demands of community justice that fail to comply with normal police procedure as may be suggested by members of CPF and at the same time wish to comply with the police procedures in dealing with a suspected criminal (Su, Mark \& Sutton, 2007). New personnel entering an orgsanisation may experience role ambiguity if an orientation to which he/she is subjected fails to provide clarity and certainty about expected performance and job behaviour. An employee who is not properly orientated is likely to experience high levels of occupational stress (Amos, Ristow, Ristow \& Pearse, 2008). Role ambiguity may be caused by a new supervisor entering an organisation. A new supervisor who is not clearly informed about the employees' expected performance and job behaviours may cause role confusion or uncertainty for employees (Chapman \& McKnight, 2003). Changes that occur in the workplace such as new appointments, transfers and promotions are positively correlated with role ambiguity. New appointments involve movement from the current or previous employer to a new employer with new terms and conditions of employment or changed job responsibilities which may create an uncertain environment thereby inducing occupational stress among such new incumbents (Medical College of Georgia, 2008). Transfers may cause role conflict because of changes in a job level or in geographical location for transferred employees thereby infusing occupational stress in transferees. Even if an organisation contemplates a transfer for an employee, the terms and conditions should remain the same prior to the transfer in order to avoid role ambiguity (Medical College of Georgia, 2008). The purpose of employee relocation should be placement an employee into a specific job so that he or she may function in his or her new job for the benefit of an organization (U.S General Services Administration, 2011). Finally, promotion occurs in a situation where an employee is placed in a higher position than the previous one within the same organisation. Slightly similar to transfer, promotion is considered to be more concerned with job enrichment. Job enrichment causes role ambiguity when an employee does not know the grounds on which he or she is privileged to make decisions (Venter, Levy, Holtzhausen, Conradie, Bendeman \& Dworzanowski-Venter, 2011). 2.3. Role overload Role overload develops when employees either feel that they lack the skills or workplace resources to complete a task or perceive that the task cannot be completed in the required amount of time (Slocum \& Hellriegel, 2007). In other words, it is an incompatibility between work demands and time available to meet the demands. Barling et al. (2005) contend that for employees to complete their roles successfully, the workload must be manageable in terms of time pressure and workplace resources. Role overload comprises quantitative and qualitative overload. Quantitative overload refers to the inability of an individual to fulfill the assigned tasks in the time available. It usually relates to time-based demands or limitations. On the other hand, qualitative overload occurs when employees do not have the skills, knowledge and abilities (SKAs) to perform the tasks adequately regardless of how much time they have (Barling et al., 2005). Quantitative overload may be experienced by an employee who does not have the ability to accomplish the assigned tasks or amount of work within a specific time frame, whereas, qualitative overload may be experienced by, for example, an unskilled employee who is promoted into a supervisory position and yet does not have relevant supervisory experience (Weinberg, Sutherland \& Cooper, 2010). Role overload can cause anxiety, depression and anger, especially when employees have no control over the amount of time available to accomplish the assigned tasks. The negative 
consequences of role overload can be reduced if managers constantly ensure that employees have increased control over their jobs (Werner, 2007). In contrast to quantitative and qualitative overload, many other employees experience quantitative and qualitative underload. Quantitative underload occurs when an employee has too little to perform on a daily basis. Quantitative underload may lead to boredom and apathy. Boredom and apathy are potentially dangerous as they could lead to occupational stress if an employee has too little to perform on a daily basis (Botha \& Pienaar, 2006). Qualitative underload occurs when an employee is not granted an opportunity to apply the acquired SKAs in an organisation in order to develop potential. A failure of managers or employers to grant an employee an opportunity to apply the acquired SKAs may result in occupational stress (Weinberg et al., 2010).

\section{The Purpose of the Study}

The purpose of the study was to assess the level of occupational stress among police officers in the Sebokeng Cluster in South Africa.

\section{Research Methodology}

\subsection{Population and sample}

The target population for this study was 1335 police officers from all ranks, race, gender and age in the Sebokeng Cluster. The Sebokeng Cluster comprised eight police stations: Sebokeng,Vanderbij|park, Evaton, Orange Farm, the Barrage, Ennerdale, Sharpeville and Boipatong. The sample size in this study was 267 (20\% of 1335). Keeping the sample size at 267 was in compliance with the suggestion of Leedy and Ormrod (2010) that $20 \%$ of the sample size should be drawn if the total population is around 1500. The sample was selected by means of a stratified sampling procedure, which is categorised as probability sampling method. The numbers of sampled police officers per stratum are shown in table 1.

Table 1: Composition of sample size per police station

\begin{tabular}{|l|c|c|}
\hline & Police officers per station & Sample size per station \\
\hline Sebokeng & 379 & 76 \\
\hline Vanderbijlpark & 361 & 72 \\
\hline Evaton & 204 & 41 \\
\hline Orange Farm & 173 & 35 \\
\hline Ennerdale & 64 & 13 \\
\hline Sharpeville & 62 & 12 \\
\hline The Barrage & 47 & 9 \\
\hline Boipatong & 45 & 9 \\
\hline Total & 1335 & $\mathbf{2 6 7}$ \\
\hline
\end{tabular}

\subsection{Instrumentation}

Data was collected by means of a self-administered structured questionnaire. The questionnaire used in this study consisted of closed-ended statements. The questionnaire comprised of two sections, A and B. Section A aimed to glean biographical information of respondents whereas Section B elicited their responses in respect of occupational stress. The questionnaire was a Five-point Likert scales questionnaire. In this questionnaire, respondents were expected to indicate whether they "strongly disagree", "disagree", "neither disagree nor agree", "agree", or "strongly agree" with the questionnaire statements. The items in this section were adapted from a variety of sources such as Rizzo, House and Lirtzman (1970), Cullen, Link, Wolfe and Frank, 1985). These authors classified occupational stress into three stressors, namely, role conflict, role ambiguity and role overload.

\subsection{Reliability and validity}

Cronbach's alpha coefficient was utilised to test the reliability of variables of the three constructs, namely, role conflict, role ambiguity and role overload. The resulting alpha values are illustrated in table 2. 
Table 2: The alpha values of occupational stressors

\begin{tabular}{|l|c|c|}
\hline Sections of the questionnaire (scale) & Cronbach's Alpha (a) & No of Items \\
\hline Section B: Role overload & .903 & 9 \\
\hline Section B: Role ambiguity & .928 & 8 \\
\hline Section B: Role conflict & .730 & 4 \\
\hline Total reliability of section B (OS) & .900 & $\mathbf{2 1}$ \\
\hline
\end{tabular}

It can be observed from table 2 that the alpha values in this study exceeded the predetermined level of .70, thereby confirming that the instrument utilised was reliable. To determine the validity of the research instrument face validity was used by distributing the questionnaire to six academics in the discipline of industrial psychology. All of the academics found that the research instrument constituted of variables relevant to occupational stress.

\section{Results and Discussion}

\subsection{Demographics}

Of the 2676 questionnaires distributed to police stations in the Sebokeng Cluster 199 were completed and returned, yielding a $75 \%$ response rate. Table 3 shows demographic information pertaining to sampled respondents. Evident from table 3 is that male police officers $(n=128 ; 64.3 \%)$ were in majority in comparison to their female respondents $(n=71$; $35.7 \%)$. Table 3 also shows that many of the respondents were constables $(n=93 ; 46.7 \%)$, and that a higher percentage of respondents $(n=53 ; 26.6 \%)$ was from the Vanderbij|park station. In contrast, Sharpeville $(n=9)$ and Boipatong $(n=9)$ stations had the lowest responses of $4.5 \%$ respectively.

Table 3: Demographic data of sampled respondents

\begin{tabular}{|c|c|c|c|}
\hline Particulars & Variables & $N$ & $\%$ \\
\hline \multirow{2}{*}{ Gender } & Females & 71 & 35.7 \\
\hline & Males & 128 & 64.3 \\
\hline \multirow{7}{*}{ Rank or position } & Brigadier & 1 & .5 \\
\hline & Colonel & 2 & 1.0 \\
\hline & Lieutenant Colonel & 15 & 7.5 \\
\hline & Captain & 29 & 14.6 \\
\hline & Warrant Officer & 37 & 18.6 \\
\hline & Sergeant & 22 & 11.1 \\
\hline & Constable & 93 & 46.7 \\
\hline \multirow{8}{*}{ Police station } & Sebokeng & 32 & 16.1 \\
\hline & Vanderbiilpark & 53 & 26.6 \\
\hline & Evaton & 41 & 20.6 \\
\hline & Orange Farm & 30 & 15.1 \\
\hline & The Barrage & 13 & 6.5 \\
\hline & Ennerdale & 12 & 6.0 \\
\hline & Sharpeville & 9 & 4.5 \\
\hline & Boipatong & 9 & 4.5 \\
\hline \multirow{5}{*}{ Age group } & Under 25 years & 5 & 2.5 \\
\hline & $25-35$ years & 80 & 40.2 \\
\hline & $36-45$ years & 53 & 26.6 \\
\hline & $46-55$ years & 57 & 28.6 \\
\hline & 56-65 years & 4 & 2.0 \\
\hline \multirow{4}{*}{ Ethnicity } & Black & 178 & 89.4 \\
\hline & Coloured & 4 & 2.0 \\
\hline & Indian & 1 & .5 \\
\hline & White & 16 & 8.0 \\
\hline \multirow{4}{*}{ Years of service } & Under 10 years & 87 & 43.7 \\
\hline & $10-15$ years & 26 & 13.1 \\
\hline & $15-20$ years & 19 & 9.5 \\
\hline & Over 20 years & 67 & 33.7 \\
\hline
\end{tabular}


Further illustrated in table 3 was that many of the respondents ( $n=80 ; 40.2 \%)$ were between the ages of 25 and 35 , in sharp contrast to the lowest percentage of respondents between the ages of 56 and $65(n=4 ; 2.0 \%)$, and under the age of $25(n=5 ; 2.5 \%)$. Reflected in table 3 is the high percentage $(n=178 ; 89.4 \%)$ of Black respondents were the lowest and percentage of Indian respondents $(n=1 ; .5 \%)$. Finally, table 4 illustrates that a greater proportion $(n=87 ; 43.7 \%)$ of sampled police officers had 10 or fewer years of service in the safety and security government department whereas respondents with years of service ranging from 15 to 20 were the lowest $(n=19 ; 9.5 \%)$.

\subsection{Frequency analysis}

Frequency analysis is used to predict how often certain values of a variable phenomenon may occur and to assess the reliability of the prediction (Leedy \& Ormrod, 2010). In the following section, the frequency analysis was performed to determine the proportion or the extent to which police officers disagree or agree with each variable or item of occupational stress. Cumulative percentage values for both "disagree" and "agree" scales were used to assess the level of occupational stress variables. Table 4 shows that sampled police officers perceived work assigned to them as manageable and it could be completed within the allocated time and that work duties did not increase all the time.

Table 4: Frequency analysis of role overload variables

\begin{tabular}{|c|c|c|}
\hline Description of Variable & $\begin{array}{c}\text { Cumulative \% } \\
\text { on disagree }\end{array}$ & $\begin{array}{c}\text { Cumulative } \% \text { on } \\
\text { agree }\end{array}$ \\
\hline It often seems like I have too much work for one person to do & 45.2 & 40.7 \\
\hline The amount of work that I am required to do seems to be increasing all the time & 34.2 & 50.2 \\
\hline I work on unnecessary things & 52.2 & 30.1 \\
\hline I am not given enough time to do what is expected of me on my job & 53.7 & 30.6 \\
\hline I need more hours in a day to do all the things which are expected of me & 52.8 & 35.2 \\
\hline Sometimes I feel as if there are not enough hours in a day & 54.8 & 30.2 \\
\hline I am unable to take sufficient breaks & 43.2 & 44.2 \\
\hline I have unrealistic time pressures & 45.7 & 33.2 \\
\hline
\end{tabular}

The data in table 4 suggests that respondents knew upfront objectives to be achieved and focused their energy and time on the attainment of the pre-set objectives. It could further be deduced that respondents had enough time to perform their work duties and were able to complete their assigned duties within the allocated time. The ability of respondents to complete assigned tasks could be attributed to the effective management by superiors who avoided assigning unmanageable assignments or tasks to their subordinates. It could further be concluded that the ability to complete assigned tasks was a result of the SKAs that police officers possess. In other words, managers assigned tasks to police officers commensurate with their SKAs. In the performance of their duties police officers are allowed to take sufficient breaks. The assertion resulting from these results was that police officers did not experience role overload in the Sebokeng Cluster. Previous study (Slocum \& Hellriegel 2007) confirms that employees were less likely to experience role overload when they were assigned with manageable number of tasks or assignments with sufficient time and resources. It could be noticed from table 5 that respondents disagreed that their work responsibilities were unclear. Furthermore, the rules that they were supposed to follow in the execution of their duties were clear.

Table 5: Frequency analysis of role ambiguity variables

\begin{tabular}{|l|c|c|}
\hline Description of Variable & Cumulative \% on disagree & Cumulative \% on agree \\
\hline My work responsibilities are very unclear to me & 80.9 & 14.1 \\
\hline The rules that we are supposed to follow seem very unclear to me & 70.9 & 16.6 \\
\hline I am unclear to whom I report/and/or who reports to me & 77.9 & 17.6 \\
\hline I am unclear of what is expected of me at work & 81.5 & 13.0 \\
\hline I feel uncertain about how much authority I have over my job & 69.3 & 21.1 \\
\hline Clear, planned goals and objectives does not exist for my job & 72.4 & 15.1 \\
\hline Explanations are unclear of what has to be done in my job & 80.4 & 11.5 \\
\hline I am unclear on what others expect of me in my job & 75.9 & 15.1 \\
\hline
\end{tabular}


In similar vein, sampled police officers disagreed that they were unclear about whom they should report to or who should report to them, hence the conception that lines of authority were clear. Additionally, sampled respondents were certain about the authority they wielded over their jobs and knew what was expected of them. It was not surprising that respondents' perception was that clear, planned goals and objectives existed for their jobs. All these findings affirmed that police officers did not experience role ambiguity in the Sebokeng Cluster. If confusion existed in respect of work demands proper explanation was offered. The previous study by Çuhadar (2008) confirms that role ambiguity is often triggered when an employee does not know what management expects him or her to accomplish. Table 6 shows that sampled respondents had to bend a rule or policy to get an assignment done. In the execution of their tasks respondents were without adequate and necessary resources, including human resources.

Table 6: Frequency analysis of role conflict variables

\begin{tabular}{|l|c|c|}
\hline Description of Variable & $\begin{array}{c}\text { Cumulative \% on } \\
\text { disagree }\end{array}$ & $\begin{array}{c}\text { Cumulative \% on } \\
\text { agree }\end{array}$ \\
\hline I sometimes have to bend a rule or policy to get an assignment done & 36.2 & 47.2 \\
\hline I often receive an assignment without adequate resources and materials to get it done & 23.1 & 66.3 \\
\hline I have to do things that should be done differently & 31.7 & 44.3 \\
\hline I receive an assignment without the manpower to complete it & 80.9 & 14.1 \\
\hline
\end{tabular}

Respondents' view was that they had to do things that had to be done differently. The data in table 6 clearly indicates that police officers in the Sebokeng Cluster experienced role conflict. The study conducted by Aamodt (2010) proves that an employee who receives two or more incompatible job demands at the same time without adequate resources is likely to be a victim of role conflict.

\section{Conclusion}

It could be concluded that the police officers in the Sebokeng Cluster did not experience role overload because they could carry out work duties within the time allocated. Similarly, police officers did not experience role ambiguity as the performance goals were clear including how to achieve them. The police officers experienced role conflict because they had incompatible work demands to accomplish without adequate resources.

\section{Recommendations}

The results emanating from the study are positive except for role conflict. In light of this research finding it could generally be recommended that management in the Sebokeng Cluster should continue the good work they were doing but should seriously consider ways in which to sustain it. To deal effectively with role overload, the top management in the Sebokeng Cluster should avoid providing police officers with conflicting demands in order for them to fulfill job demands; ensure provision of sufficient time, resources and materials for execution of their duties; provide sufficient and clear information and certainty about employees' expected performance and job behaviours; and coach police officers regarding their work.

\section{Suggestions for Future Research}

The current study assessed the level of occupational stress among police officers in the Sebokeng Cluster. Future research could conduct longitudinal study on the level of occupational stress among police officers. Further research could determine the level occupational stressors other than role overload, role conflict and role ambiguity among police officers.

\section{References}

Aamodt, M.G. (2010). Industrial/Organisational Psychology: an applied approach. $6^{\text {th }}$ ed. Belmont: Wadsworth Cengage Learning. Amos, T.L., Ristow, A., Ristow, L., \& Pearse, N.J. (2008). Human Resource Management. 3rd ed. Cape Town: Juta. Barling, J., Kelloway, E.K., \& Frone, M.R. (2005). Handbook of Work Stress. New Delhi: SAGE Publications.

Biseul, X. (2011). Health capsule: Do you know what technostress is? http://www.01net. com/article/267724.pdf.

Botha, C., \& Pienaar, J. (2006). South African correctional official occupational stress: The role of psychological strengths. Journal of Criminal Justice, 34, 73-84. 
Bucker, H., \& Wiecko, F. (2007). Testing the effect of common police stressors on the Turkish National Police. An International Journal of Police Strategies \& Management, 30(2), 291-309.

Chapman, E.N., \& McKnight, W. (2003). The New Supervisor: stepping up with confidence. $4^{\text {th }}$ ed. Boston: Thomson.

Çuhadar, M.T. (2008). The sectoral analysis of role conflict and role ambiguity with job satisfaction and organisational commitment: A study in the East Mediterranean Region. Journal of Global Strategic Management, (04), 108-117.

De Sousa, M.F. (2009). Relationship between work and non-work stressors and work-life balance amongst global market trading professional. Unpublished Master's dissertation, University of South Africa: Pretoria.

DuBrin, A.J. (2002). Fundamentals of Organisational Behaviour. Ohio: Jack W. Calhoun.

Eighner, L. (2009). Social structure and interaction in everyday life. Chaper 4 review. 98-127. [Online]. http://fasnafan.tripod.com/ socialstructure.pdf.

Jorgensen, L.I., \& Rothmann, S. (2008). Occupational stress, ill health and organisational commitment of members of the South African Police Service in the North West Province. Acta Criminologica, 21(2), 1-15.

Kaiser, H. F. (1974). An index of factor simplicity. Psychometrika, 39, 31-36.

Leedy, P.D., \& Ormrod, J.E. (2010). Practical Research: planning and design. New Jersey: Kevin M. Davis.

Matthewman, L., Rose, A., \& Hetherington, A. (2009). Work Psychology. New York: Oxford University Press.

Medical College of Georgia. (2008). Relocation and moving expenses for new employees. Administrative Policy Library, 1-17.

Mohr, A.T., \& Puck, J.F. (2003). Inter-sender role conflicts, general manager satisfaction and joint venture performance in IndianGerman joint venture. Working Paper, 03/19.

Richardson, K.M., \& Rothstein, H.R. (2008). Effects of occupational stress management intervention programs: A Meta-Analysis. Journal of Occupational Health Psychology, 13(1), 69-93.

Rizzo, J., House, R., \& Lirtzman, S. (1970). Role conflict and ambiguity in complex organisations. Administrative Science Quarterly, 15, 150-163.

Slocum, J.W., \& Hellriegel, D. (2007). Fundamentals of Organisational Behaviour. California: Melissa S. Acunã.

Steiber, N. (2009). Reported levels of time-based and strain-based conflict between work and family roles in Europe: A multilevel approach. Institute of Sociology and Social Research, 470-488. Vienna: Springer Science. http://cadmus.eui.eu/handle/ 1814/13480.

Su, N.M., Mark, G., \& Sutton, S.A. (2007). Workplace connectors as facilitators for work. http://www.ics.uci.edu/ gmark/C\&T\%2007.pdf.

U.S General Services Administration (GSA). (2011). Handbook for relocating federal employees. Office of Government wide Policy, 131.

Vecchio, P.R. (2000). Organisational Behaviour. Orlando: Mike Roche, Harcourt College Publisher.

Venter, R., Levy, A., Holtzhausen, M., Conradie, M., Bendeman, H., \& Dworzanowski-Venter, B. (2011). Labour Relations in South Africa. $4^{\text {th }}$ ed. Cape Town: Oxford University Press.

Weinberg, A., Sutherland, V.J., \& Cooper, C. (2010). Organisational Stress Management: a strategic approach. New York: Palgrave Macmillan.

Werner, A. (2007). Organisational Commitment: a contemporary South African perspective. Pretoria: Van Schaik.

Yu, J.C., Kuo, L.H., Chen, L.M., Yang, H.J., Yang, H.H., \& Hu, W.C. (2009). Assessing and managing mobile technostress. WSEAS Transactions on Communications, 8(4), 416-425. 